\title{
Inhibition of DNA methyltransferase activity and expression by treatment with the pan-deacetylase inhibitor panobinostat in hepatocellular carcinoma cell lines
}

\author{
Steffen Zopf ${ }^{*}$, Matthias Ocker ${ }^{4}$, Daniel Neureiter ${ }^{2}$, Beate Alinger ${ }^{2}$, Susanne Gahr ${ }^{1,3}$, Markus F Neurath ${ }^{1}$ \\ and Pietro Di Fazio ${ }^{4}$
}

\begin{abstract}
Background: Hepatocellular carcinoma (HCC) still represents an unmet medical need. Epigenetic inactivation of tumor suppressor genes like RASSF1A or APC by overexpression of DNA methyltransferases (DNMTs) has been shown to be common in HCC and to be linked to the overall prognosis of patients. Inhibitors of protein and histone deacetylases (DACi) have been demonstrated to possess strong anti-tumor effects in HCC models.
\end{abstract}

Methods: We therefore investigated whether DACi also has any influence on the expression and activity of DNMTs and methylated target genes in HepG2 and Hep3B cell culture systems and in a xenograft model by immunohistochemistry, westernblotting, RT-gPCR and methylation-specific PCR.

Results: Our findings demonstrate a rapid inhibition of DNMT activity $6 \mathrm{~h}$ after treatment with $0.1 \mu \mathrm{M}$ of the pan-DACi panobinostat. A downregulation of DNMT mRNAs and protein were also observed at later points in time. This loss of DNMT activity and expression was paralleled by a diminished methylation of the target genes RASSF1A and APC and a concomitant re-expression of APC mRNA and protein. Analysis of HepG2 xenograft specimens confirmed these results in vivo.

Conclusion: We suggest a dual mode of action of DACi on DNA methylation status: a rapid inhibition of enzyme activity due to interference with posttranslational acetylation and a delayed effect on transcriptional control of DNMT genes by HDAC or miRNA mechanisms.

Keywords: DNA methyltransferase, Deacetylase inhibitor, Epigenetics, Transcriptional control, Hepatocellular carcinoma

\section{Background}

Hepatocellular carcinoma (HCC) is the most common primary tumor of the liver and represents an unmet medical need, being among the most common tumor diseases and causes of cancer related deaths worldwide and showing a rising incidence also in Western countries [1-3]. Although the multi-kinase inhibitor sorafenib has recently been approved for treatment of advanced stage HCC, the overall efficacy still remains dissatisfying [4].

\footnotetext{
* Correspondence: steffen.zopf@uk-erlangen.de

${ }^{1}$ Department of Medicine 1, University Hospital Erlangen, Ulmenweg 18, Erlangen 91054, Germany

Full list of author information is available at the end of the article
}

Besides genetic alterations, changes in chromatin have recently been identified to contribute to tumorigenesis [5]. These reversible modifications are considered to contribute to tumor suppressor gene inactivation by means of DNA methylation, histone modifications or miRNA expression. Expression of DNA methyltransferases (DNMT) has been shown to be associated with liver cancer formation and DNA hypermethylation [6,7], especially in the presence of hepatitis B or hepatitis C viruses [8-10] and has been linked to poor prognosis [11]. Today, three DNMTs have been identified in human cells. While DNMT1 methylates newly synthesized DNA during cell division (maintenance DNMT), DNMT3a and DNMT3b act on methylation of CpG

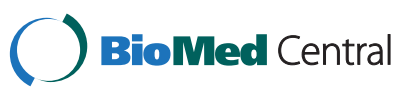


motifs during cellular differentiation and regulatory processes (de novo DNMT) [12]. Genes that are commonly affected by DNA methylation include both the tumor suppressors RASSF1A (Ras association domain family 1 isoform A) and also APC (adenomatous polyposis coli). Both genes have been shown to be commonly inactivated in human hepatocellular carcinoma and to influence the overall prognosis of patients and therefore represent interesting targets for reversing DNA methylation status [13-17].

Besides DNA methylation, post-translational modifications such as acetylation, SUMOylation or phosphorylation occurring at amino acid residues in histone proteins have also been identified as strong epigenetic regulators of gene transcription. Previously, we have shown that expression of histone deacetylases (HDAC) is significantly associated with HCC grading and that HDAC2 represents an independent prognostic factor in HCC [18]. While inhibition of HDAC is usually attributed to transcriptional control of cell cycle regulators like p21 $1^{\text {cip1/waf1 }}[19]$, additional effects involving nonnuclear protein modifications have recently been described, e.g. the interaction with chaperones such as heat shock protein 90 (HSP90) [20,21]. Although these cellular targets of deacetylases are not well known today, some reports confirm a transcriptional control of DNMT by HDAC $[22,23]$.

Panobinostat is a novel orally available pan-deacetylase inhibitor with broad anti-tumor activity [24]. Our own previous results showed a significant inhibition of HCC growth in vitro and in xenograft models in vivo which were mediated by alternative pathways of apoptosis induction such as activation of the unfolded protein response [25]. We therefore investigated whether panobinostat also influences the activity of DNMT in HCC cell lines and if this affects the expression and methylation status of CpG promoter islands of known tumor suppressor genes in HCC models. We can show here that panobinostat exerts a dual effect on DNMT activity and expression, indicating that deacetylase inhibitors can also indirectly control DNA methylation status.

\section{Methods}

\section{Cell culture}

The human hepatocellular carcinoma cell lines HepG2 $\left(\mathrm{p} 53^{\mathrm{wt}}\right)$ and Hep3B ( $553^{-/-}$) were cultured on six-well tissue culture plates (Becton Dickinson, Mannheim, Germany) in RPMI-1640 (Biochrom, Berlin, Germany) or Dulbecco's modified Eagle's medium (DMEM, Biochrom, Berlin, Germany) containing 10\% fetal calf serum (Biochrom), penicillin (107 U/l) and streptomycin $(10 \mathrm{mg} / \mathrm{l})$ at $37{ }^{\circ} \mathrm{C}$ in an atmosphere containing $5 \% \mathrm{CO}$. All cell lines were obtained from the German Collection of Microorganisms and Cell Cultures (DSMZ, Braunschweig,
Germany). Cells were starved for $24 \mathrm{~h}$ in medium containing $0.125 \%$ FCS to achieve cell cycle synchronization and then washed twice with phosphate-buffered saline (PBS; Biochrom), treated with trypsin EDTA (0.05\% Trypsin, $0.02 \%$ EDTA; Biochrom), seeded at a density of $0.5 \times 10^{6}$ per well [25]. Panobinostat was a gift from Novartis Pharma AG, Basel, Switzerland, and was dissolved in dimethylsulfoxide (DMSO; Sigma, Deisenhofen, Germany) and then further diluted with culture medium [25]. Cells were treated with $0.1 \mu \mathrm{M}$ panobinostat for 6 to $72 \mathrm{~h}$ and then processed for further analyses.

\section{HepG2 xenograft samples}

Samples from previously established xenografts of HepG2 cells to male athymic nu/nu NMRI mice (Harlan Winkelmann GmbH, Borchen, Germany) were used for this study [25]. HepG2 cell lines were harvested and resuspended in sterile physiologic $\mathrm{NaCl}$ solution. $5.0 \times 10^{6}$ cells were injected subcutaneously into the flank of 6 to 8 week old male mice (mean weight $38.2+/-4.3 \mathrm{~g}$ ). Eight animals were used for each treatment group. Animals were kept in a light and temperature controlled environment and provided with food and water ad libitum. Tumor size was determined daily by measurement using a caliper square. When subcutaneous tumors reached a diameter of $7 \mathrm{~mm}$, daily i.p. treatment with panobinostat $(10 \mathrm{mg} / \mathrm{kg})$ or vehicle (physiologic saline solution) was started. Animals were sacrificed by cervical dislocation and tumor samples collected after 1, 7 and 28 days of treatment or when reaching the termination criteria (e.g. weight loss $>20 \%$, tumor diameter $>25 \mathrm{~mm}$ or tumor ulceration through the skin). Tumor and tissue samples were fixed in 10\% phosphate-buffered formalin or snap-frozen in liquid nitrogen. All animals received humane care. The study protocol complied with the institute's guidelines and was approved by the Government of Lower Franconia (Würzburg, Germany, file number 54-2531.31-3/06) prior to the commencement of the experiments. Hep3B cells proved not to be tumorigenic in NMRI mice and were therefore not used for in vivo experiments.

\section{Measurement of DNMT activity}

Nuclear protein was isolated with EpiQuik ${ }^{\text {tix }}$ Nuclear Extraction Kit I (Epigentek, Brooklyn, NY, USA) from cells exposed to panobinostat or from untreated control cells. After protein quantification with Total Protein Kit (Micro Lowry, Peterson's Modification; Sigma-Aldrich Chemie $\mathrm{GmbH}$, Munich, Germany), $12 \mu \mathrm{g}$ of nuclear protein was used to measure total DNMT activity with the EpiQuik ${ }^{\text {Tm }}$ DNA Methyltransferase Activity/ Inhibition Assay (Epigentek) in accordance with the manufacturer's instructions. 
Isolation of total RNA and quantitative real-time RT-PCR Total cellular RNA was extracted using the RNeasy Kit (Qiagen, Hilden, Germany) in accordance with the manufacturer's instructions. Reverse transcription into cDNA was performed using Superscript III RNAse H-reverse transcriptase (Live Technologies, Darmstadt, Germany) with dT15 (TIB-Biomol, Berlin, Germany) and random hexamer primers (Promega, Heidelberg, Germany) as previously described [26]. QuantiTect Primers for DNMT1, DNMT3a, DNMT3b, APC, RASSF1A and GAPDH were purchased from Qiagen and subjected to quantitative real-time RT-PCR on a LightCycler system (Roche Molecular Biochemicals, Mannheim, Germany) using the LightCycler FastStart DNA Master SYBR Green I Kit (Roche Molecular Biochemicals). Results were analyzed with the LightCycler software and normalized to GAPDH mRNA content for each sample.

\section{Quantitative methylation-specific real-time PCR}

Total DNA was extracted from cell culture samples and tissue specimens from nude mice by using the DNeasy Blood and Tissue Kit (Qiagen). DNA was then subjected to sodium bisulfate conversion using the EpiTect Bisulfite Kit (Qiagen). Bisulfite converted DNA was then used to perform a quantitative methylation-specific PCR (qMSP) with primers and TaqMan probes (see Table 1) specific for nucleotide sequences containing methylated cytosines at CpG positions [27]. qMSP was performed using the EpiTect MethyLight PCR Kit (Qiagen) in accordance with the manufacturer's instructions.

\section{Protein extraction and Westernblot analysis}

Whole cell lysates were prepared from panobinostattreated cells, untreated controls and xenograft tissue samples as previously described [28]. Total protein was

Table 1 Primer and TaqMan probe sequences for qMSP

\begin{tabular}{|c|c|}
\hline APC & \\
\hline Forw. & 5'-AGTGCGGGTCGGGAAGC-3' \\
\hline Rev. & 5'-AACCACATATCGATCACGTACG-3' \\
\hline TaqMan-Probe: & $\begin{array}{l}\text { 5'-FAM-AAAACGCCCTAATCCGCATCCAACG- } \\
\text { TAMRA-3' }\end{array}$ \\
\hline PCR parameter: & $\begin{array}{l}\text { Denaturation: } 95^{\circ} \mathrm{C}, 10 \mathrm{~min} \text {. (1 cycle), } \\
\text { Amplification: } 95^{\circ} \mathrm{C}, 10 \mathrm{sec} \text {; } 64^{\circ} \mathrm{C}, 60 \mathrm{sec} .(50 \mathrm{cycle}) ; \\
\text { Denaturation: } 40^{\circ} \mathrm{C}, 30 \mathrm{sec} \text { ( }(1 \mathrm{cycle})\end{array}$ \\
\hline \multicolumn{2}{|l|}{ RASSF1A } \\
\hline Forw. & 5'-GCG TTG AAG TCG GGG TTC-3' \\
\hline Rev. & $5^{\prime}$-CCC GTA CTT CGC TAA CTT TAA ACG-3' \\
\hline TaqMan-Probe: & $\begin{array}{l}\text { 5'-FAM-ACAAACGCGAACCGAACGAAACCA- } \\
\text { TAMRA-3M }\end{array}$ \\
\hline PCR parameter: & $\begin{array}{l}\text { Denaturation: } 95^{\circ} \mathrm{C}, 10 \mathrm{~min} .(1 \mathrm{cycle}), \\
\text { Amplification: } 95^{\circ} \mathrm{C}, 10 \mathrm{sec} . ; 63^{\circ} \mathrm{C}, 60 \mathrm{sec} .(50 \mathrm{cycle}) ; \\
\text { Denaturation: } 40^{\circ} \mathrm{C}, 30 \mathrm{sec} \text { ( }(1 \mathrm{cycle})\end{array}$ \\
\hline
\end{tabular}

extracted from cultured cells by adding $2 \mathrm{X}$ sample buffer (10 mM sodium chloride, 0.5\% Nonidet NP40 (Amresco, Solon, OH, USA), 20 mM Tris- $\mathrm{HCl}$ pH 7.4, 5 mM magnesium chloride, $10 \mu \mathrm{g} / \mathrm{ml}$ complete protease inhibitor cocktail (Roche Diagnostics, Mannheim, Germany), $1 \mathrm{mM}$ phenylmethylsulfonylfluoride). DNA was shared by pipetting up and down for 3 minutes at room temperature. Samples were boiled at $95^{\circ} \mathrm{C}$ for 15 minutes, centrifuged at 13,000 rpm for 10 seconds and then subjected to $14 \%$ SDS-PAGE (Life Technologies). After blocking overnight at $4{ }^{\circ} \mathrm{C}$ in a buffer containing PBS, $0.1 \%$ Tween-20 and 5\% low fat milk powder, nitrocellulose membranes were incubated for 90 minutes with primary antibodies. Antibodies against DNMT1, DNMT3a, DNMT3b (Cell Signaling Technology, Denvers, MA, USA), APC, RASSF1A (both from Abcam, Cambridge, UK) and $\beta$-actin (Sigma, Deisenhofen, Germany) were used. Membranes were washed three times for 10 minutes in a buffer containing PBS and 0.1\% Tween-20 and were incubated with a peroxidase coupled secondary antibody (1:1,000, Pierce, Rockland, IL, USA) to visualize responsive bands after incubation with West Pico luminescence substrate (Pierce). Densitometry analysis was performed by peak intensity analysis on a GeneGnome image capture and analysis system (GeneGnome, Syngene, UK). Bands were normalized to $\beta$-actin expression which was used as an internal loading control.

\section{Immunohistochemistry}

Formalin-fixed and paraffin-embedded xenograft tumour samples were cut into $5 \mu \mathrm{m}$ sections deparaffinised using graded alcohols. Antigen retrieval was performed by heat-induced epitope retrieval in $\mathrm{pH}=9$ antigen retrieval buffer (Dako, Glostrup, Denmark) at $95^{\circ} \mathrm{C}$ for 60 minutes. Endogenous peroxidase blocking was carried out for 10 minutes with peroxidase blocking reagent (Dako). Subsequently, the primary antibody against DNMT1 (monoclonal, mouse anti-human, Antibodies-Online, Aachen, Germany, ABIN466002, 1:50) and DNMT3a (polyclonal, rabbit anti-human, Santa Cruz Biotechnology, Heidelberg, Germany, sc-20703, 1:200) was applied for 30 minutes at RT. For detection of the primary antibodies the ready-to-use REAL $^{\mathrm{TM}}$ EnVision $^{\mathrm{TM}}$ Detection System (Dako) was used in accordance with the manufacturer's instructions. The EnVision staining system is based on an HRP labeled dextran polymer, which is conjugated to secondary antibodies eliminating the nonspecific staining background resulting from endogenous avidin-biotin activity. Visualization was performed using diaminobenzidine (DAB) as the chromogen substrate being a part of the REAL ${ }^{\mathrm{Tm}}$ EnVision ${ }^{\mathrm{Tm}}$ Detection System. Slides were counterstained with hematoxylin. The stained slides were digitalized using the ImageAccess 9 Enterprise software (Imagic Bildverarbeitung, Glattbrugg, 
Switzerland). The percentage numbers of DNMT1 and DNMT3a nuclear expressing tumor cells were evaluated for the 3 different high power fields (400 magnification) using the particle analysis module with the optimized binarisation method of the image analysis system.

\section{Statistical analysis}

Statistical analysis was performed using SPSS 15.0.1 for Windows (SPSS Inc., Chicago, IL, USA). Significance was calculated using the $t$-test for paired samples. $\mathrm{P}<0.05$ was regarded as significant $(*)$.

\section{Results}

\section{Panobinostat inhibits DNMT activity and expression} in vitro

After only $6 \mathrm{~h}$ of treatment, incubation of HepG2 and Hep3B cells led to a rapid and significant decrease in total DNMT activity by $46.7 \%$ and $47.4 \%$, respectively. At later points in time, DNMT activity was stably reduced by approximately $20 \%$ in both cell lines, except for the 24 and $72 \mathrm{~h}$ time point in HepG2, where an inhibition of more than $40 \%$ was observed (Figure 1A).

Expression of DNMT1, DNMT3a and DNMT3b were then investigated by quantitative real-time RT-PCR. Panobinostat treatment significantly repressed mRNA for DNMT1 and DNMT3a in both cell lines while no changes were observed in DNMT3b levels (Figure 1B/C). These findings were corroborated by westernblot analysis showing a strong reduction of DNMT1 and DNMT3a protein in both cell lines but not of DNMT3b (Figure 2). Here, only a transient decrease in protein levels was observed after 24 to $48 \mathrm{~h}$ in both cell lines. Although mRNA levels in total were rapidly decreased by panobinostat, protein expression was significantly reduced after only $24 \mathrm{~h}$ and remained suppressed until $72 \mathrm{~h}$ for DNMT1 and DNMT3a.

\section{Effects of panobinostat on target gene methylation and expression in vitro}

We next investigated whether the inhibition of DNMT activity and expression is also reflected on the methylation pattern of known hypermethylated tumor suppressor genes. In order to do so, quantitative methylation specific PCR was performed for APC and RASSF1A in cells treated with $0.1 \mu \mathrm{M}$ panobinostat for 6 to $72 \mathrm{~h}$ and expressed relative to the levels of untreated controls at the given points in time (Figure 3). Overall, Hep3B cells seemed to be more sensitive to the DACi-mediated inhibition of DNA methylation as shown by a significant and strong reduction of methylated APC after only $6 \mathrm{~h}$. While methylation was suppressed by approximately $80 \%$ here, APC methylation returned to the level of untreated controls after $24 \mathrm{~h}$. RASSF1A showed a slight reduction in methylation at $12 \mathrm{~h}$ but only proved to be

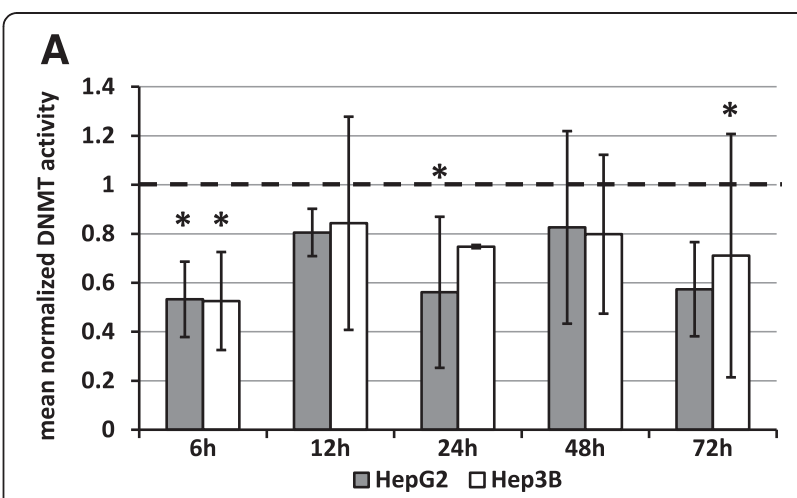

B
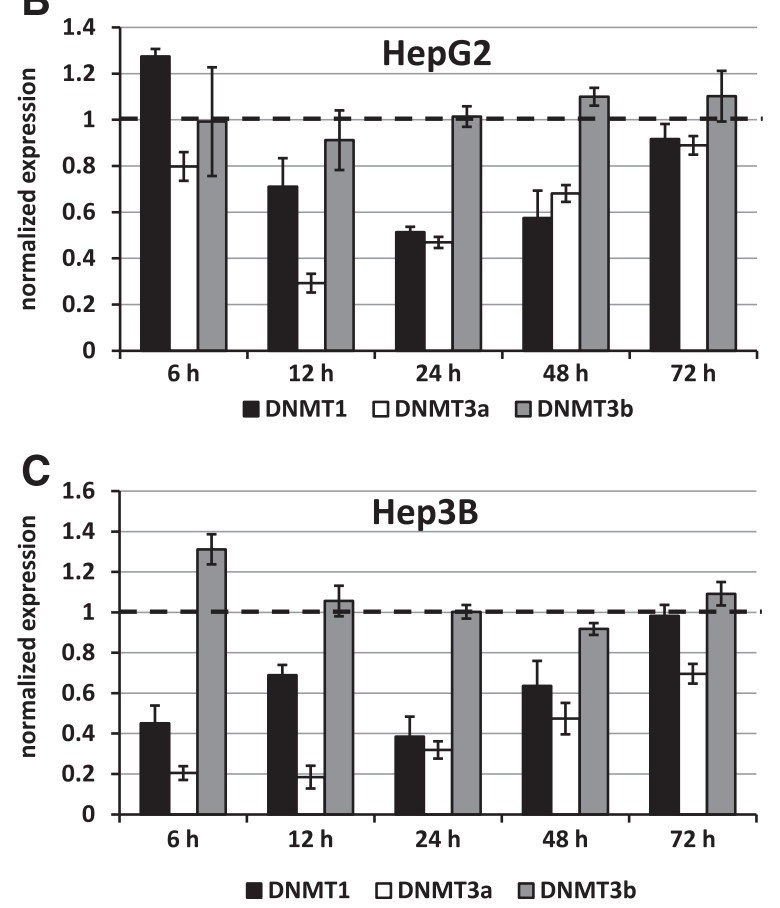

Figure 1 Panobinostat affects activity and expression of DNA methyltransferases in vitro. (A) Total DNMT activity was evaluated in HepG2 and Hep3B cells treated with $0.1 \mu \mathrm{M}$ panobinostat for the indicated points in time. Results are the mean remaining DNMT activity \pm relative error of three independent experiments and are expressed relative to values of untreated controls with a set value of 1.0 for each point in time. ${ }^{*} P<0.05$ vs. untreated controls. (B) and (C) Quantitative RT-PCR analysis of expression of DNMTs in HepG2 (B) and Hep3B (C) cells after treatment with $0.1 \mu \mathrm{M}$ panobinostat. Results were normalized to the GAPDH level of each sample and represent mean \pm relative error of three independent experiments and are expressed relative to mRNA levels of untreated controls at each point in time using the set value 1.0.

significant (60\% reduction) at $72 \mathrm{~h}$. In HepG2, APC methylation was significantly reduced after only $24 \mathrm{~h}$ of treatment while no change was observed for RASSF1A. In line with the reduction of methylation, an increased expression of APC was observed in both cell lines, reaching the highest level at $48 \mathrm{~h}$ for Hep3B and at $72 \mathrm{~h}$ 


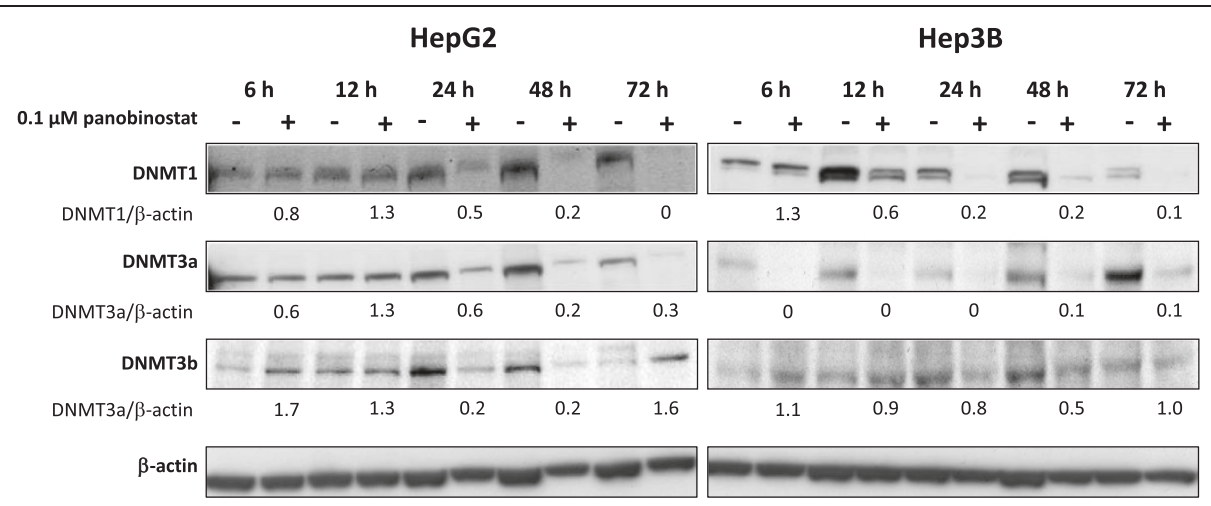

Figure 2 Westernblot analysis of DNMT expression. HepG2 and Hep3B cells were incubated with $0.1 \mu$ M panobinostat for the indicated points in time. Western blot results show representative examples for expression of DNMT1, DNMT3a and DNMT3b as well as $\beta$-actin which served as an internal control. Densitometry values are relative to untreated controls with a set value of 1.0 for each point in time.

for HepG2, respectively (Figure 3C). Observation of methylation of RASSF1A showed no significant change in expression induced by panobinostat (Figure 3D).

\section{Panobinostat influences methylation and gene expression pattern in vivo}

To address whether panobinostat also influences expression of DNMTs and related target genes in vivo, we analyzed HepG2 xenograft samples from a previously described nude mouse model [25]. Animals were treated with daily intraperitoneal injections of $10 \mathrm{mg} / \mathrm{kg}$ panobinostat. After only 1 day expression of all DNMTs were reduced by approximately $40 \%$ compared to untreated controls. The observed reduction in expression was statistically significant $(P<0.05)$ for DNMT1 and DNMT3a (Figure 4A). Although expression of DNMT3b was also reduced in the in vivo setting, the results were not of statistical significance $(P=0.06,0.28$ and 0.08 at day 1,7 and 28 , respectively), and therefore confirmed the above described in vitro findings.

The methylation status and total mRNA expression of APC and RASSF1A were analyzed from these samples after 7 and 28 days of treatment (Figure 4B). Interestingly, while the methylation status of APC did not differ
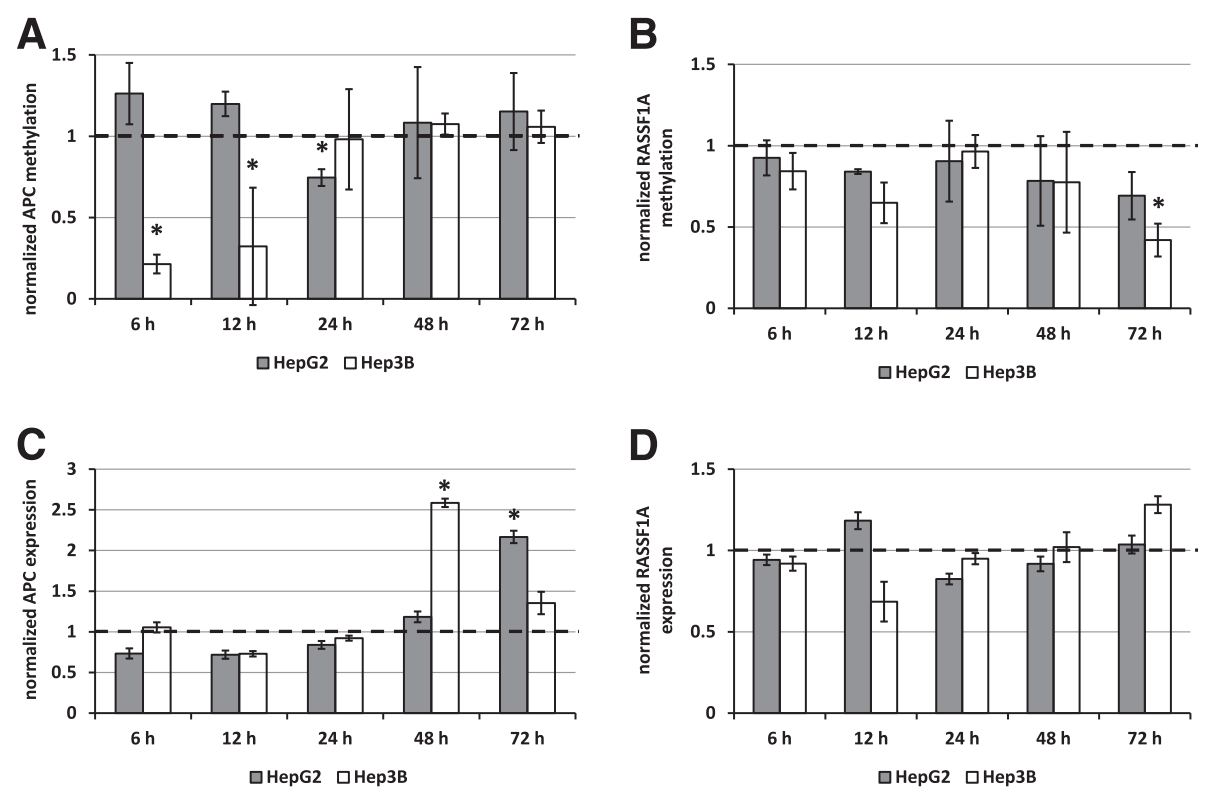

Figure 3 Regulation of DNA methylation and expression of target genes after panobinostat treatment. DNA methylation of APC (A) and RASSF1A (B) was detected by quantitative methylation-specific PCR in HepG2 and Hep3B cells treated with $0.1 \mu \mathrm{M}$ panobinostat. Expression of total mRNA for APC (C) and RASSF1A (D) was analyzed using quantitative real-time RT-PCR and normalization to GAPDH content of each sample. Results are mean \pm relative error of three independent experiments and are expressed relative to the untreated controls with a set value of 1.0 . * $P<0.05$ vs. untreated controls. 

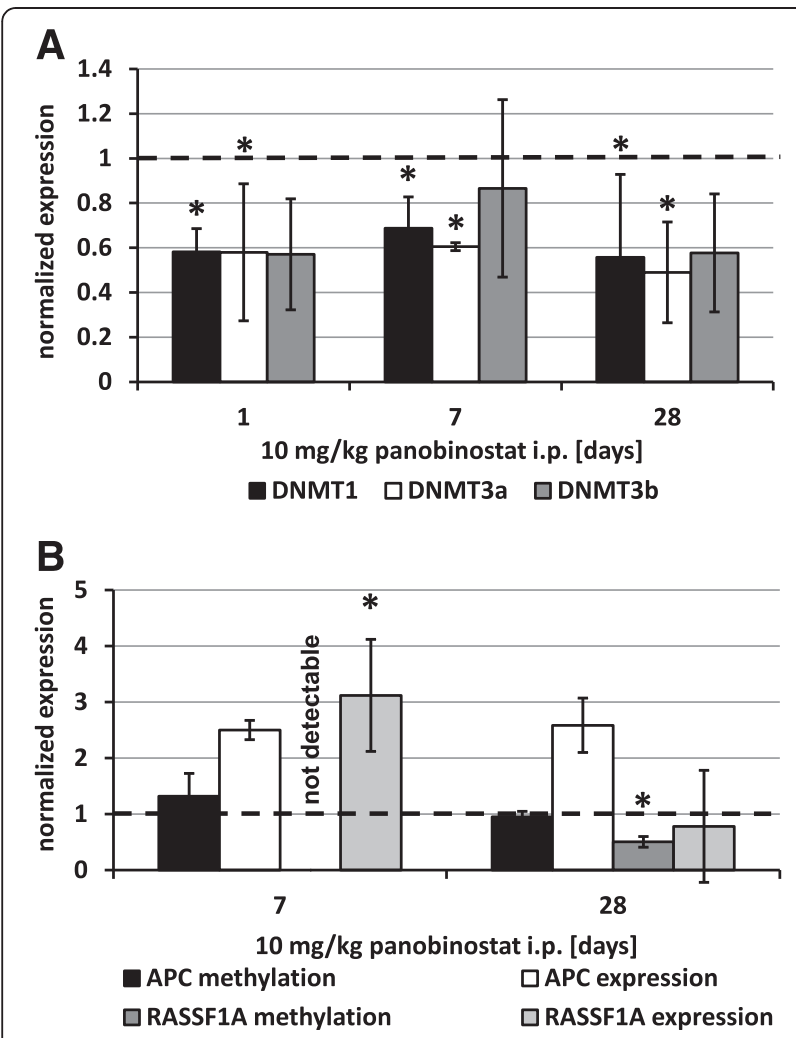

Figure 4 Effect of panobinostat on DNMT and target gene expression in vivo. HepG2 xenograft specimens were analyzed for expression of (A) DNMTs after 1, 7 and 28 days of daily i.p. injections of $10 \mathrm{mg} / \mathrm{kg}$ panobinostat. Results were normalized to the GAPDH content of each sample and represent mean \pm relative error of 5 to 10 independent samples per group and are expressed relative to expression levels of untreated control animals with the set value of 1.0 for each point in time. (B) Methylation status and total expression level of APC and RASSF1A were analyzed at day 7 and day 28 of panobinostat treatment. Results are normalized to levels of untreated controls. Methylation of RASSF1A was not detectable in untreated controls and in treated animals at day $7 .{ }^{*} P<0.05$ vs. untreated controls.

as compared to untreated controls, the expression of APC was induced 2.5-fold. Methylated RASSF1A was not detectable at day 7 in either the untreated controls or the treated animals, however, a reduction of approximately $50 \%$ was measured at the end of the study period in the treated animals as compared to the controls. Expression of RASSF1A was not elevated at this point in time but showed a significant increase at day 7 .

These results were confirmed by immunohistochemical analyses after 28 days of treatment with $10 \mathrm{mg} / \mathrm{kg}$ panobinostat (Figure 5). Nuclear expression of both DNMT1 and DNMT3a was significantly reduced in HepG2 xenograft samples. While DNMT1 and DNMT3a were expressed in $83.3 \%$ and $84.6 \%$ of all cells in untreated controls, only $10.7 \%$ and $20.0 \%$ stained positive for these markers at the end of the treatment period.

\section{Discussion}

Gene silencing by epigenetic mechanisms like DNA methylation or histone acetylation has been shown to contribute to HCC development [29-31]. These epigenetic mechanisms alone or in combination with genetic modifications like mutations can lead to the inactivation of tumor suppressor genes such as RASSF1A or APC and thus promote hepatocarcinogenesis [32-36]. While RASSF1A has been demonstrated to be hypermethylated in several series of clinical HCC specimens, other potential candidates such as p16 (CDKN2a), retinoic acid receptor (RAR) or $\mathrm{H}$-cadherin $(\mathrm{CDH} 13)$ are reported to be low or unmethylated and were therefore not considered to be suitable target genes for our study $[30,37,38]$. The reversal of epigenetically silenced genes has therefore received increasing attention recently and various studies aimed at reversing the hypermethylated or hypoacetylated phenotype in tumors. Promising preclinical results using DNMT inhibitors like 5-azacytidine, 5-aza-2'-deoxycytidine or zebularine have been obtained in HCC models [39-41]. Similarly, various histone deacetylase inhibitors, e.g. trichostatin A, SAHA, or the novel pan-deacetylase inhibitor panobinostat have been investigated in HCC cell culture and animal models showing a high efficacy in inhibiting tumor cell growth. Furthermore, we recently reported a good safety profile of panobinostat in combination with sorafenib in a patient with metastatic HCC [25,42-44]. While the classically considered mode of action of these compounds is regarded as interfering with chromatin structure and regulating the accessibility of transcriptional complexes to the DNA [19], recent evidence suggests that modifying non-histone proteins contributes to the potent effects of deacetylase inhibitors in cancer cells $[25,45]$. In line with this view, recent data confirms that DNMTs can also be inhibited by deacetylase inhibitors $[23,46]$. We have demonstrated here for the first time that treatment with the pan-deacetylase inhibitor panobinostat rapidly reduces the activity of DNMT1 and DNMT3a in two liver cancer cell lines in vitro after only $6 \mathrm{~h}$ of incubation and independent of their p 53 status while the expression of these enzymes is affected only at later points in time. These data indicate that panobinostat leads to a rapid inactivation of the enzymatic function of DNMTs, probably by interfering with the protein folding and acetylation status of these proteins which is also reflected by a rapid decrease in the methylation levels of APC. This hypothesis is supported by a recent report on novel acetylation sites in lysine residues of DNMT1 that could be influenced by class III HDAC enzymes [47]. DNMT1 was also shown to be stabilized by HDAC1 mediated deacetylation and protection from proteasomal degradation, which represents a target of panobinostat, indicating a cross-dependency of acetylation and protein function [46]. Additionally, it was also demonstrated that 


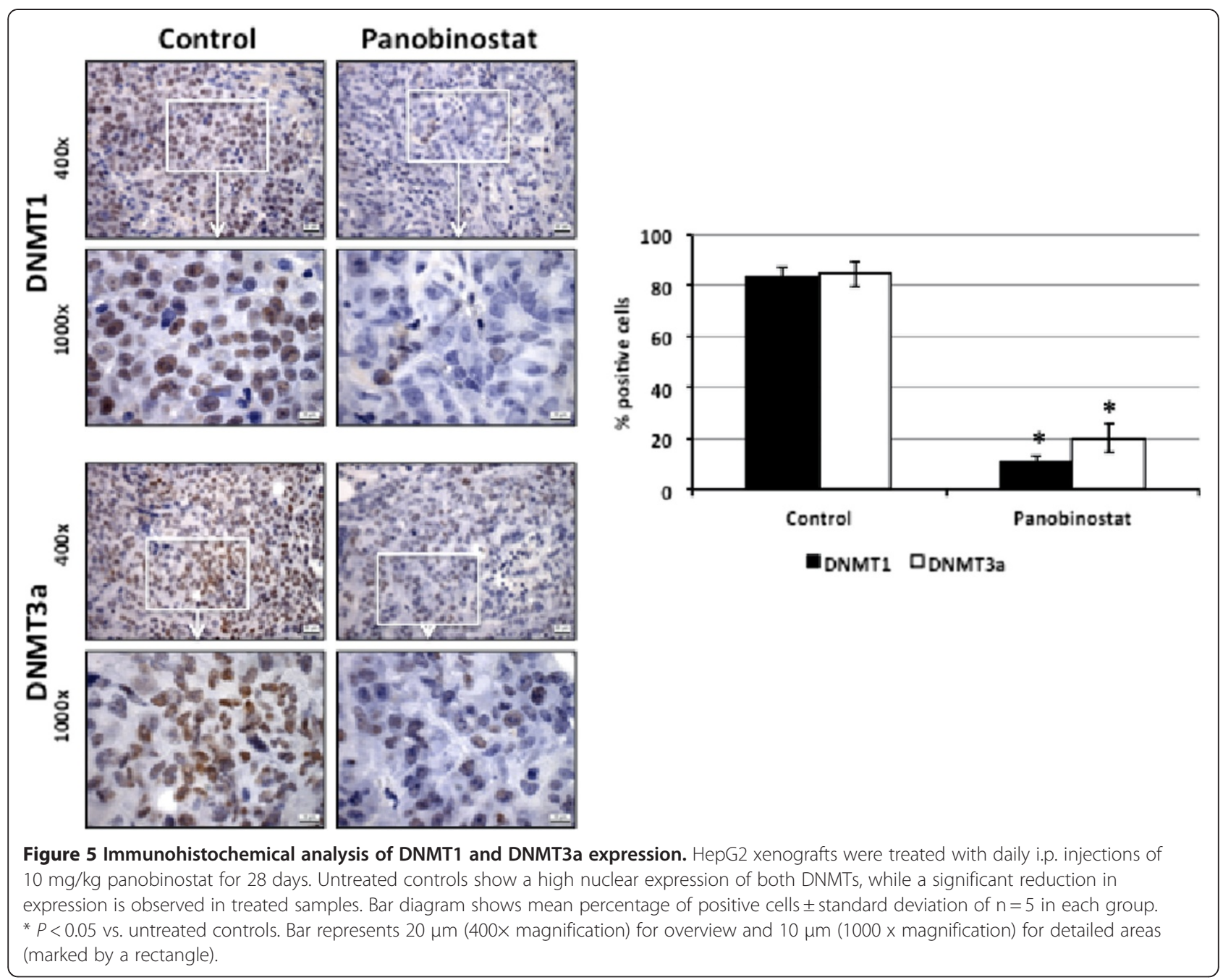

inhibition of deacetylase function leads to ubiquitinmediated degradation of DNMT1 and could thus also contribute to the reduced expression observed in our model [48]. The here observed delayed downregulation of DNMT mRNA and protein could also be attributed to a decreased mRNA stability as was previously demonstrated for DNMT1 and DNMT3b after treatment with Trichostatin A in Jurkat or endometrial cells [23,49]. Panobinostat was shown to downregulate DNMT1 without affecting DNMT3a and 3b in human breast cancer cells and human acute leukemia cells while we observed an additional effect on DNMT3a in the used HCC cell lines [48,50]. Here we found a downregulation of total DNMT activity and suppression of DNMT1 and DNMT3a protein expression but not of DNMT3b. In contrast to the known concept of maintenance and de novo DNMTs, it was shown that the loss DNMT1 can be compensated by DNMT3b [51,52], confirming our results of a residual DNMT activity after panobinostat treatment. These findings demonstrate divergent effects of deacetylase inhibitor treatment on individual DNMTs dependent on the cell type and the intracellular context. Additional regulatory effects responsible for this phenomenon could involve the altered miRNA profile after treatment with deacetylase inhibitors [53-55]. We have previously shown that panobinostat is a strong modulator of miRNA expression in liver cancer cell lines [56] and it was also demonstrated by others that various miRNAs, e.g. miR-29, miR-148 or miR-185, can regulate the expression of DNMTs [57-61] and thus crosslink deacetylase inhibition to mechanisms of DNA methylation $[22,23,62]$.

Interestingly, panobinostat affects the expression of the maintenance DNMT1 and of DNMT3a, which is (together with DNMT3b) considered as a de novo DNA methyltransferase acting during DNA replication and cell division [12]. An overexpression of DNMTs has previously been reported in HCC, in precancerous cirrhotic lesions and in dysplasias, indicating a strong contribution of epigenetic events in HCC development $[6,7,11,33,63]$. In line with our previously reported data on inhibition of 
cell proliferation by panobinostat [25], a secondary and delayed effect on target gene methylation and reexpression was observed in both cell lines for APC at 48 and $72 \mathrm{~h}$, respectively. We therefore propose a dual mode of action of pan-deacetylase inhibitors such as panobinostat on epigenetic control of gene expression: deacetylase inhibitors primarily influence the acetylation status and function of various cytosolic and nuclear proteins including DNMTs. The rapid inhibition of DNMT activity could be attributed to alterations in the protein folding due to impaired acetylation. This also influences the turnover of affected proteins and could lead to the previously described activation of the unfolded protein response and induction of non-canonical apoptosis pathways [25]. Deacetylase function also controls the acetylation status of histones which, together with DNMTs and putative miRNAs, control transcriptional processes. This not only leads to the well described upregulation of tumor suppressor genes such as p2 $1^{\text {cip1/waf1 }}$ [19], but also to the suppression of DNMT expression and alterations in miRNA profiles $[53,62]$ which additionally affect the translational processes leading to the desired growthinhibitory and pro-apoptotic effects of deacetylase inhibitors in tumor cells.

\section{Conclusion}

In summary, our data indicates that, in addition to the epigenetic activity, deacetylase inhibitors act on protein folding and function which mediates various additional effects such as activation of the unfolded protein response or transcriptional and translational control of tumor suppressor genes. Further studies are urgently required in order to better understand this multitude of effects (in particular the effects on miRNA and cellular acetylome).

\section{Competing interests}

M.O. received honoraria and funding from Novartis Pharma AG, Nuremberg, Germany, the manufacturer of panobinostat. The other authors declare no competing interests.

\section{Authors' contributions}

SZ planned and performed the experiments and drafted the manuscript. PDF carried out the in vivo experiments and supervised the data. DN and BA carried out the immunohistochemistry. SG performed the RT-qPCR experiments. MFN supervised the data and drafted the manuscript. MO designed the study, supervised the data and drafted the manuscript. All authors read and approved the final manuscript.

\section{Acknowledgements}

We are grateful for the excellent technical assistance of Astrid Taut, Christina Lindner and Isabel Zeitträger. This study was supported by a grant from the ELAN fund of the Faculty of Medicine, Friedrich-Alexander University of Erlangen-Nuremberg to S.Z. (09.03.16.1.), a grant of the University Hospital Medical Center Giessen and Marburg (UKGM) to M.O. and an EASL Dame Sheila Sherlock post-doctoral fellowship to P.D.F.

\section{Author details}

'Department of Medicine 1, University Hospital Erlangen, Ulmenweg 18, Erlangen 91054, Germany. ${ }^{2}$ Institute of Pathology, Paracelsus Medical University, Salzburg, Austria. ${ }^{3}$ Department of Pneumology, Klinikum
Nuremberg Nord, Nuremberg, Germany. ${ }^{4}$ Institute for Surgical Research, Philipps University Marburg, Marburg, Germany.

Received: 19 April 2012 Accepted: 31 August 2012

Published: 3 September 2012

\section{References}

1. Siegel R, Naishadham D, Jemal A: Cancer statistics, 2012. CA Cancer J Clin 2012, 62:10-29.

2. Bosetti C, Levi F, Boffetta P, Lucchini F, Negri E, La Vecchia C: Trends in mortality from hepatocellular carcinoma in Europe, 1980-2004. Hepatology 2008, 48:137-145.

3. El-Serag HB, Rudolph KL: Hepatocellular carcinoma: epidemiology and molecular carcinogenesis. Gastroenterology 2007, 132:2557-2576.

4. Duffy A, Greten T: Developing better treatments in hepatocellular carcinoma. Expert Rev Gastroenterol Hepatol 2010, 4:551-560.

5. Hatziapostolou M, lliopoulos D: Epigenetic aberrations during oncogenesis. Cell Mol Life Sci 2011, 68:1681-1702.

6. Park HJ, Yu E, Shim YH: DNA methyltransferase expression and DNA hypermethylation in human hepatocellular carcinoma. Cancer Lett 2006, 233:271-278.

7. Oh BK, Kim H, Park HJ, Shim YH, Choi J, Park C, Park YN: DNA methyltransferase expression and DNA methylation in human hepatocellular carcinoma and their clinicopathological correlation. Int J Mol Med 2007, 20:65-73.

8. Park IY, Sohn BH, Yu E, Suh DJ, Chung YH, Lee JH, Surzycki SJ, Lee YI: Aberrant epigenetic modifications in hepatocarcinogenesis induced by hepatitis B virus X protein. Gastroenterology 2007, 132:1476-1494.

9. Arora $\mathrm{P}$, Kim EO, Jung JK, Jang KL: Hepatitis $\mathrm{C}$ virus core protein downregulates E-cadherin expression via activation of DNA methyltransferase 1 and 3b. Cancer Lett 2008, 261:244-252.

10. Zheng DL, Zhang L, Cheng N, Xu X, Deng Q, Teng XM, Wang KS, Zhang X, Huang J, Han ZG: Epigenetic modification induced by hepatitis B virus $X$ protein via interaction with de novo DNA methyltransferase DNMT3A. J Hepatol 2009, 50:377-387.

11. Saito $Y$, Kanai $Y$, Nakagawa T, Sakamoto M, Saito H, Ishii H, Hirohashi S: Increased protein expression of DNA methyltransferase (DNMT) 1 is significantly correlated with the malignant potential and poor prognosis of human hepatocellular carcinomas. Int J Cancer 2003, 105:527-532.

12. Schneider-Stock R, Ocker M: Epigenetic therapy in cancer: molecular background and clinical development of histone deacetylase and DNA methyltransferase inhibitors. IDrugs 2007, 10:557-561.

13. Donninger H, Vos MD, Clark GJ: The RASSF1A tumor suppressor. J Cell Sci 2007, 120:3163-3172.

14. Jain S, Chang TT, Hamilton JP, Lin SY, Lin YJ, Evans AA, Selaru FM, Lin PW, Chen SH, Block TM, et al: Methylation of the CpG sites only on the sense strand of the APC gene is specific for hepatocellular carcinoma. PLoS One 2011, 6:e26799.

15. Liu JB, Zhang YX, Zhou SH, Shi MX, Cai J, Liu Y, Chen KP, Qiang FL: CpG island methylator phenotype in plasma is associated with hepatocellular carcinoma prognosis. World J Gastroenterol 2011, 17:4718-4724.

16. Saelee $P$, Wongkham S, Chariyalertsak S, Petmitr S, Chuensumran U: RASSF1A promoter hypermethylation as a prognostic marker for hepatocellular carcinoma. Asian Pac J Cancer Prev 2010, 11:1677-1681.

17. Honda S, Haruta M, Sugawara W, Sasaki F, Ohira M, Matsunaga T, Yamaoka H, Horie H, Ohnuma N, Nakagawara A, et al: The methylation status of RASSF1A promoter predicts responsiveness to chemotherapy and eventual cure in hepatoblastoma patients. Int I Cancer 2008, 123:1117-1125.

18. Quint K, Agaimy A, Di Fazio P, Montalbano R, Steindorf C, Jung R, Hellerbrand C, Hartmann A, Sitter H, Neureiter D, Ocker M: Clinical significance of histone deacetylases 1, 2, 3, and 7: HDAC2 is an independent predictor of survival in HCC. Virchows Arch 2011, 459:129-139.

19. Ocker $M$, Schneider-Stock R: Histone deacetylase inhibitors: signalling towards p21cip1/waf1. Int J Biochem Cell Biol 2007, 39:1367-1374.

20. Li D, Marchenko ND, Moll UM: SAHA shows preferential cytotoxicity in mutant p53 cancer cells by destabilizing mutant $\mathrm{p} 53$ through inhibition of the HDAC6-Hsp90 chaperone axis. Cell Death Differ 2011, 18:1904-1913. 
21. Peng L, Seto E: Deacetylation of nonhistone proteins by HDACs and the implications in cancer. Handb Exp Pharmacol 2011, 206:39-56.

22. You JS, Kang JK, Lee EK, Lee JC, Lee SH, Jeon YJ, Koh DH, Ahn SH, Seo DW, Lee HY, et al: Histone deacetylase inhibitor apicidin downregulates DNA methyltransferase 1 expression and induces repressive histone modifications via recruitment of corepressor complex to promoter region in human cervix cancer cells. Oncogene 2008, 27:1376-1386.

23. Xiong Y, Dowdy SC, Podratz KC, Jin F, Attewell JR, Eberhardt NL, Jiang SW: Histone deacetylase inhibitors decrease DNA methyltransferase-3B messenger RNA stability and down-regulate de novo DNA methyltransferase activity in human endometrial cells. Cancer Res 2005, 65:2684-2689.

24. Prince HM, Bishton MJ, Johnstone RW: Panobinostat (LBH589): a potent pan-deacetylase inhibitor with promising activity against hematologic and solid tumors. Future Oncol 2009, 5:601-612.

25. Di Fazio P, Schneider-Stock R, Neureiter D, Okamoto K, Wissniowski T, Gahr S, Quint K, Meissnitzer M, Alinger B, Montalbano R, et al: The pandeacetylase inhibitor panobinostat inhibits growth of hepatocellular carcinoma models by alternative pathways of apoptosis. Cell Oncol 2010 32:285-300

26. Neureiter D, Zopf S, Leu T, Dietze O, Hauser-Kronberger C, Hahn EG, Herold C, Ocker M: Apoptosis, proliferation and differentiation patterns are influenced by Zebularine and SAHA in pancreatic cancer models. Scand I Gastroenterol 2007, 42:103-116.

27. Moribe T, lizuka N, Miura T, Kimura N, Tamatsukuri S, Ishitsuka $H_{\text {, }}$ Hamamoto Y, Sakamoto K, Tamesa T, Oka M: Methylation of multiple genes as molecular markers for diagnosis of a small, well-differentiated hepatocellular carcinoma. Int J Cancer 2009, 125:388-397.

28. Zopf $\mathrm{S}$, Neureiter D, Bouralexis $\mathrm{S}, \mathrm{Abt} \mathrm{T}$, Glaser KB, Okamoto K, GansImayer M, Hahn EG, Herold C, Ocker M: Differential response of p53 and p21 on HDAC inhibitor-mediated apoptosis in HCT116 colon cancer cells in vitro and in vivo. Int J Oncol 2007, 31:1391-1402.

29. Shen J, Wang S, Zhang YJ, Kappil M, Wu HC, Kibriya MG, Wang Q, Jasmine F, Ahsan $\mathrm{H}$, Lee PH, et al: Genome-wide DNA methylation profiles in hepatocellular carcinoma. Hepatology 2012, 55:1799-1808.

30. Lambert MP, Paliwal A, Vaissiere T, Chemin I, Zoulim F, Tommasino M, Hainaut P, Sylla B, Scoazec JY, Tost J, Herceg Z: Aberrant DNA methylation distinguishes hepatocellular carcinoma associated with HBV and HCV infection and alcohol intake. J Hepatol 2011, 54:705-715.

31. Um TH, Kim H, Oh BK, Kim MS, Kim KS, Jung G, Park YN: Aberrant CpG island hypermethylation in dysplastic nodules and early HCC of hepatitis B virus-related human multistep hepatocarcinogenesis. J Hepatol 2011, 54:939-947.

32. Hu L, Chen G, Yu H, Qiu X: Clinicopathological significance of RASSF1A reduced expression and hypermethylation in hepatocellular carcinoma. Hepatol Int 2010, 4:423-432.

33. Kondo Y, Shen L, Suzuki S, Kurokawa T, Masuko K, Tanaka Y, Kato H, Mizuno $Y$, Yokoe M, Sugauchi F, et al: Alterations of DNA methylation and histone modifications contribute to gene silencing in hepatocellular carcinomas. Hepatol Res 2007, 37:974-983

34. Yeo W, Wong $N$, Wong WL, Lai PB, Zhong S, Johnson PJ: High frequency of promoter hypermethylation of RASSF1A in tumor and plasma of patients with hepatocellular carcinoma. Liver Int 2005, 25:266-272.

35. Csepregi A, Rocken C, Hoffmann J, Gu P, Saliger S, Muller O, Schneider-Stock R, Kutzner N, Roessner A, Malfertheiner P, Ebert MP: APC promoter methylation and protein expression in hepatocellular carcinoma. J Cancer Res Clin Oncol 2008, 134:579-589.

36. Lee S, Lee HJ, Kim JH, Lee HS, Jang JJ, Kang GH: Aberrant CpG island hypermethylation along multistep hepatocarcinogenesis. Am J Pathol 2003, 163:1371-1378.

37. Yu J, Ni M, Xu J, Zhang H, Gao B, Gu J, Chen J, Zhang L, Wu M, Zhen S, Zhu J: Methylation profiling of twenty promoter-CpG islands of genes which may contribute to hepatocellular carcinogenesis. BMC Cancer 2002, 2:29.

38. Yang B, Guo M, Herman JG, Clark DP: Aberrant promoter methylation profiles of tumor suppressor genes in hepatocellular carcinoma. Am J Pathol 2003, 163:1101-1107.

39. Calvisi DF, Ladu S, Gorden A, Farina M, Conner EA, Lee JS, Factor VM, Thorgeirsson SS: Ubiquitous activation of Ras and Jak/Stat pathways in human HCC. Gastroenterology 2006, 130:1117-1128.
40. Venturelli S, Berger A, Weiland T, Zimmermann M, Hacker S, Peter C, Wesselborg S, Konigsrainer A, Weiss TS, Gregor M, et al: Dual antitumour effect of 5-azacytidine by inducing a breakdown of resistance-mediating factors and epigenetic modulation. Gut 2011, 60:156-165.

41. Hirasawa Y, Arai M, Imazeki F, Tada M, Mikata R, Fukai K, Miyazaki M, Ochiai $\mathrm{T}$, Saisho H, Yokosuka O: Methylation status of genes upregulated by demethylating agent 5-aza-2'-deoxycytidine in hepatocellular carcinoma. Oncology 2006, 71:77-85.

42. Gahr S, Wissniowski T, Zopf S, Strobel D, Pustowka A, Ocker M: Combination of the deacetylase inhibitor panobinostat and the multikinase inhibitor sorafenib for the treatment of metastatic hepatocellular carcinoma - review of the underlying molecular mechanisms and first case report. J Cancer 2012, 3:158-165.

43. Ocker M, Alajati A, Ganslmayer M, Zopf S, Luders M, Neureiter D, Hahn EG, Schuppan D, Herold C: The histone-deacetylase inhibitor SAHA potentiates proapoptotic effects of 5-fluorouracil and irinotecan in hepatoma cells. J Cancer Res Clin Oncol 2005, 131:385-394.

44. Herold C, Ganslmayer M, Ocker M, Hermann M, Geerts A, Hahn EG, Schuppan D: The histone-deacetylase inhibitor Trichostatin A blocks proliferation and triggers apoptotic programs in hepatoma cells. $J$ Hepatol 2002, 36:233-240.

45. Ocker M: Deacetylase inhibitors - focus on non-histone targets and effects. World J Biol Chem 2010, 1:55-61.

46. Du Z, Song J, Wang Y, Zhao Y, Guda K, Yang S, Kao HY, Xu Y, Willis J, Markowitz SD, et al: DNMT1 stability is regulated by proteins coordinating deubiquitination and acetylation-driven ubiquitination. Sci Signal 2010, 3:ra80.

47. Peng L, Yuan Z, Ling H, Fukasawa K, Robertson K, Olashaw N, Koomen J, Chen J, Lane WS, Seto E: SIRT1 deacetylates the DNA methyltransferase 1 (DNMT1) protein and alters its activities. Mol Cell Biol 2011, 31:4720-4734.

48. Zhou Q, Agoston AT, Atadja P, Nelson WG, Davidson NE: Inhibition of histone deacetylases promotes ubiquitin-dependent proteasomal degradation of DNA methyltransferase 1 in human breast cancer cells. Mol Cancer Res 2008, 6:873-883.

49. Januchowski R, Dabrowski M, Ofori H, Jagodzinski PP: Trichostatin A downregulate DNA methyltransferase 1 in Jurkat T cells. Cancer Lett 2007, 246:313-317.

50. Fiskus W, Buckley K, Rao R, Mandawat A, Yang Y, Joshi R, Wang Y, Balusu R, Chen J, Koul S, et al: Panobinostat treatment depletes EZH2 and DNMT1 levels and enhances decitabine mediated de-repression of JunB and loss of survival of human acute leukemia cells. Cancer Biol Ther 2009, 8:939-950.

51. Rhee I, Jair KW, Yen RW, Lengauer C, Herman JG, Kinzler KW, Vogelstein B, Baylin SB, Schuebel KE: CpG methylation is maintained in human cancer cells lacking DNMT1. Nature 2000, 404:1003-1007.

52. Rhee I, Bachman KE, Park BH, Jair KW, Yen RW, Schuebel KE, Cui $H_{\text {, }}$ Feinberg AP, Lengauer C, Kinzler KW, et al: DNMT1 and DNMT3b cooperate to silence genes in human cancer cells. Nature 2002, 416:552-556.

53. Lee EM, Shin S, Cha HJ, Yoon Y, Bae S, Jung JH, Lee SM, Lee SJ, Park IC, Jin YW, An S: Suberoylanilide hydroxamic acid (SAHA) changes microRNA expression profiles in A549 human non-small cell lung cancer cells. Int J Mol Med 2009, 24:45-50

54. Delcuve GP, Khan DH, Davie JR: Roles of histone deacetylases (HDACs) in epigenetic regulation: emerging paradigms from studies with inhibitors. Clin Epigenetics 2012, 4:5

55. Sampath D, Liu C, Vasan K, Sulda M, Puduvalli VK, Wierda WG, Keating MJ: Histone deacetylases mediate the silencing of miR-15a, miR-16, and miR-29b in chronic lymphocytic leukemia. Blood 2012, 119:1162-1172

56. Di Fazio P, Montalbano R, Neureiter D, Alinger B, Schmidt A, Merkel AL, Quint K, Ocker M: Downregulation of HMGA2 by the pan-deacetylase inhibitor panobinostat is dependent on hsa-let-7b expression in liver cancer cell lines. Exp Cell Res 2012, 318:1832-1843.

57. Braconi C, Huang N, Patel T: MicroRNA-dependent regulation of DNA methyltransferase-1 and tumor suppressor gene expression by interleukin-6 in human malignant cholangiocytes. Hepatology 2010, 51:881-890

58. Fabbri M, Garzon R, Cimmino A, Liu Z, Zanesi N, Callegari E, Liu S, Alder $\mathrm{H}$, Costinean S, Fernandez-Cymering C, et al: MicroRNA-29 family reverts aberrant methylation in lung cancer by targeting DNA methyltransferases 3A and 3B. Proc Natl Acad Sci U S A 2007, 104:15805-15810. 
59. Zhang Z, Tang H, Wang Z, Zhang B, Liu W, Lu H, Xiao L, Liu X, Wang R, Li X, et al: MiR-185 targets the DNA methyltransferases 1 and regulates global DNA methylation in human glioma. Mol Cancer 2011, 10:124.

60. Pan W, Zhu S, Yuan M, Cui H, Wang L, Luo X, Li J, Zhou H, Tang Y, Shen N: MicroRNA-21 and microRNA-148a contribute to DNA hypomethylation in lupus CD4+ T cells by directly and indirectly targeting DNA methyltransferase 1.J Immunol 2010, 184:6773-6781.

61. Denis H, Ndlovu MN, Fuks F: Regulation of mammalian DNA methyltransferases: a route to new mechanisms. EMBO Rep 2011, 12:647-656.

62. Rhodes LV, Nitschke AM, Segar HC, Martin EC, Driver JL, Elliott S, Nam SY, Li M, Nephew KP, Burow ME, Collins-Burow BM: The histone deacetylase inhibitor trichostatin A alters microRNA expression profiles in apoptosisresistant breast cancer cells. Oncol Rep 2012, 27:10-16.

63. Choi MS, Shim YH, Hwa JY, Lee SK, Ro JY, Kim JS, Yu E: Expression of DNA methyltransferases in multistep hepatocarcinogenesis. Hum Pathol 2003, 34:11-17.

doi:10.1186/1471-2407-12-386

Cite this article as: Zopf et al: Inhibition of DNA methyltransferase activity and expression by treatment with the pan-deacetylase inhibitor panobinostat in hepatocellular carcinoma cell lines. BMC Cancer 2012 $12: 386$

\section{Submit your next manuscript to BioMed Central and take full advantage of:}

- Convenient online submission

- Thorough peer review

- No space constraints or color figure charges

- Immediate publication on acceptance

- Inclusion in PubMed, CAS, Scopus and Google Scholar

- Research which is freely available for redistribution 